\title{
Distúrbios da aquisição da linguagem e da aprendizagem
}

\author{
Language and learning disorders
}

\author{
Carolina R. Schirmer ${ }^{1}$, Denise R. Fontoura ${ }^{1}$, Magda L. Nunes ${ }^{2}$
}

\section{Resumo}

Objetivo: $\mathrm{O}$ objetivo deste artigo é instrumentalizar os profissionais da saúde, em especial o pediatra, para que possam agir no diagnóstico e na prevenção primária dos distúrbios de linguagem oral e escrita.

Fontes dos dados: Foi realizada revisão da literatura sobre o tema proposto na MEDLINE nos últimos 5 anos e foram incluídas referências de livros-texto considerados como base para a compreensão dos distúrbios da linguagem e do aprendizado na infância.

Síntese dos dados: Sabe-se que as causas de alterações de linguagem e de dificuldades de aprendizagem podem ser variadas, apesar de existirem muitos estudos indicando fatores neurológicos para tais problemas.

Conclusão: Ressalta-se a importância de uma adequada investigação buscando um correto diagnóstico para, então, direcionar o melhor tratamento indicado para cada caso.

J Pediatr (Rio J). 2004;80(2 Supl):S95-S103: Distúrbios da linguagem, aprendizagem, dislexia, autismo, epilepsia.

\section{Abstract}

Objective: To aid health professionals, especially pediatricians, in the diagnosis and prevention of language and learning disorders.

Sources of data: Review of the relevant literature published in the past 5 years (MEDLINE and textbooks).

Summary of the findings: Multiple variables, among them neurological diseases, may be related to the etiology of language and learning disorders.

Conclusion: An adequate diagnostic investigation may guide the choice of treatment.

\section{Introdução}

Grande parte das queixas relatadas na clínica pediátrica, neurológica, neuropsicológica e fonoaudiológica infantil refere-se a alterações no processo de aprendizagem e/ou atraso na aquisição da linguagem.

Acredita-se que as dificuldades de aprendizagem estejam intimamente relacionadas a história prévia de atraso na aquisição da linguagem. As dificuldades de linguagem referem-se a alterações no processo de desenvolvimento da expressão e recepção verbal e/ou escrita. Por isso, a necessidade de identificação precoce dessas alterações no curso normal do desenvolvimento evita posteriores conseqüências educacionais e sociais desfavoráveis ${ }^{1}$.

1. Fonoaudióloga. Aluna do curso de Mestrado em Medicina e Ciências da Saúde, Programas de Neurologia Infantil e Neuropsicologia, Serviço de Neurologia, Hospital São Lucas, Pontifícia Universidade Católica do Rio Grande do Sul (PUCRS).

2. Professora adjunta de Neurologia e Pediatria, Faculdade de Medicina, PUCRS.

J Pediatr (Rio J). 2004;80(2 Supl):S95-S103: Language disorders, learning disorders, dyslexia, autism, epilepsy.

O objetivo deste estudo é instrumentalizar os profissionais da saúde, em especial o pediatra, para que possam agir no diagnóstico e na prevenção primária dos distúrbios de linguagem oral e escrita. Para tornar a leitura mais didática, enfocamos inicialmente o processo normal de desenvolvimento da linguagem, as causas neurobiológicas e ambientais dessas alterações, tentando relacioná-las com suas implicações nas diversas fases do desenvolvimento. Ao final de cada tópico, descreve-se uma breve abordagem terapêutica.

\section{Linguagem}

A linguagem é um exemplo de função cortical superior, e seu desenvolvimento se sustenta, por um lado, em uma estrutura anatomofuncional geneticamente determinada e, por outro, em um estímulo verbal que depende do ambiente 2 . 
Serve de veículo para a comunicação, ou seja, constitui um instrumento social usado em interações visando à comunicação. Desta forma, deve ser considerada mais como uma força dinâmica ou processo do que como um produto. Pode ser definida como um sistema convencional de símbolos arbitrários que são combinados de modo sistemático e orientado para armazenar e trocar informações ${ }^{3}$.

\section{Desenvolvimento da linguagem}

Muito antes de começar a falar, a criança está habilitada a usar o olhar, a expressão facial e o gesto para comunicarse com os outros. Tem também capacidade para discriminar precocemente os sons da fala. A aprendizagem do código lingüístico se baseia no conhecimento adquirido em relação a objetos, ações, locais, propriedades, etc. Resulta da interação complexa entre as capacidades biológicas inatas e a estimulação ambiental e evolui de acordo com a progressão do desenvolvimento neuropsicomotor ${ }^{1,4}$.

Apesar de não estar completamente esclarecido o grau de eficácia com que a linguagem é adquirida, sabe-se que as crianças de diferentes culturas parecem seguir o mesmo percurso global de desenvolvimento da linguagem. Ainda antes de nascer, elas iniciam a aprendizagem dos sons da sua língua nativa e desde os primeiros meses distinguemna de línguas estrangeiras ${ }^{3,5}$.

No desenvolvimento da linguagem, duas fases distintas podem ser reconhecidas: a pré-lingüística, em que são vocalizados apenas fonemas (sem palavras) e que persiste até aos 11-12 meses; e, logo a seguir, a fase lingüística, quando a criança começa a falar palavras isoladas com compreensão. Posteriormente, a criança progride na escalada de complexidade da expressão. Este processo é contínuo e ocorre de forma ordenada e seqüencial, com sobreposição considerável entre as diferentes etapas deste desenvolvimento ${ }^{6}$ (Tabela 1 ).

O processo de aquisição da linguagem envolve o desenvolvimento de quatro sistemas interdependentes: o pragmático, que se refere ao uso comunicativo da linguagem num contexto social; o fonológico, envolvendo a percepção e a produção de sons para formar palavras; o semântico, respeitando as palavras e seu significado; e o gramatical, compreendendo as regras sintáticas e morfológicas para combinar palavras em frases compreensíveis. Os sistemas fonológico e gramatical conferem à linguagem a sua forma.

Tabela 1 - Desenvolvimento da linguagem

\begin{tabular}{lll}
\hline Receptivo & Idade & Expressivo
\end{tabular}

Assusta-se.

Aquieta-se ao som de voz.

Vira-se para a fonte de voz.

Observa com atenção objetos e fatos do ambiente.

Responde com tons emotivos à voz materna.

Entende pedidos simples com dicas através de gestos. Entende "não" e "tchau".

Entende muitas palavras familiares e ordens simples associadas a gestos. Ex.: "vem com o papai".

Conhece algumas partes do corpo.

Acha objetos a pedido.

Brincadeira simbólica com miniaturas.

Segue instruções envolvendo dois conceitos verbais (os quais são substantivos). Ex.: "coloque o copo na caixa".

Entende primeiros verbos. Entende instruções envolvendo até três conceitos. Ex. "coloque a boneca grande na cadeira".

Conhece diversas cores. Reconhece plurais, pronomes que diferenciam os sexos, adjetivos.

Começa a aprender conceitos abstratos (duro, mole, liso). Linguagem usada para raciocínio.

Entende "se", "por que", "quanto".

Compreende 1.500 a 2.000 palavras.
0-6 semanas

3 meses

6 meses

9 meses

12 meses

18 meses

24 meses

30 meses

36 meses

48 meses
Choros diferenciados e sons primitivos. Aparecem os sons vogais (V).

Primeiras consoantes (C) ouvidas são p/b e k/g. Inicia balbucio.

Balbucio (seqüências de CVCV sem mudar a consoante). Ex.: "dudadá".

Imita sons.

Jargão.

Balbucio não-reduplicativo

(seqüência CVC ou VCV).

Começa a dizer as primeiras palavras, como "mamá", "papá" ou "dadá".

Poderá ter de 30 a 40 palavras

("mamá", "bebê", "miau", "pé", "ão-ão", "upa"). Começa a combinar duas palavras ("dá papá").

Tem um vocabulário de cerca de 150 palavras. Usa combinação de duas ou três.

Usa habitualmente linguagem telegráfica ("bebê", "papá pão", "mamã vai papá").

Inicia o uso de artigos, plurais, preposições e verbos auxiliares.

Formula frases corretas, faz perguntas, usa a negação, fala de acontecimentos no passado ou antecipa outros no futuro. 
O sistema pragmático descreve o modo como a linguagem deve ser adaptada a situações sociais específicas, transmitindo emoções e enfatizando significados ${ }^{5}$.

A intenção de comunicar-se pode ser demonstrada de forma não-verbal através da expressão facial, sinais, e também quando a criança começa a responder, esperar pela vez, questionar e argumentar. Essa competência comunicativa reflete a noção de que o conhecimento da adequação da linguagem a determinada situação e a aprendizagem das regras sociais de comunicação é tão importante quanto o conhecimento semântico e gramatical ${ }^{3}$.

\section{Bases biológicas da linguagem}

O processo da linguagem é bastante complexo e envolve uma rede de neurônios distribuída entre diferentes regiões cerebrais. Em contato com os sons do ambiente, a fala engloba múltiplos sons que ocorrem simultaneamente, em várias freqüências e com rápidas transições entre estas. 0 ouvido tem de sintonizar este sinal auditivo complexo, decodificá-lo e transformá-lo em impulsos elétricos, os quais são conduzidos por células nervosas à área auditiva do córtex cerebral, no lobo temporal. O logo, então, reprocessa os impulsos, transmite-os às áreas da linguagem e provavelmente armazena a versão do sinal acústico por um certo período de tempo ${ }^{2}$.

A área de Wernicke, situada no lobo temporal, reconhece o padrão de sinais auditivos e interpreta-os até obter conceitos ou pensamentos, ativando um grupo distinto de neurônios para diferentes sinais. Ao mesmo tempo, são ativados neurônios na porção inferior do lobo temporal, os quais formam uma imagem do que se ouviu, e outros no lobo parietal, que armazenam conceitos relacionados. De acordo com este modelo, a rede neuronal envolvida forma uma complexa central de processamento.

Para verbalizar um pensamento, acontece o inverso. Inicialmente, é ativada uma representação interna do assunto, que é canalizada para a área de Broca, na porção inferior do lobo frontal, e convertida nos padrões de ativação neuronal necessários à produção da fala. Também estão envolvidas na linguagem áreas de controle motor e as responsáveis pela memória7.

O cérebro é um órgão dinâmico que se adapta constantemente a novas informações. Como resultado, as áreas envolvidas na linguagem de um adulto podem não ser as mesmas envolvidas na criança, e é possível que algumas zonas do cérebro sejam usadas apenas durante o período de desenvolvimento da linguagem ${ }^{8}$.

Acredita-se que o hemisfério esquerdo seja dominante para a linguagem em cerca de $90 \%$ da população; contudo, o hemisfério direito participa do processamento, principalmente nos aspectos da pragmática ${ }^{9,10}$.

\section{Etiologia dos distúrbios da linguagem oral e escrita}

A fala caracteriza-se habitualmente quanto à articulação, ressonância, voz, fluência/ritmo e prosódia. As alterações da linguagem situam-se entre os mais freqüentes problemas do desenvolvimento, atingindo 3 a $15 \%$ das crianças, e podem ser classificadas em atraso, dissociação e desvio ${ }^{11}$ (Tabela 2).

Tabela 2 - Classificação das alterações da linguagem

\begin{tabular}{ll}
\hline Atraso & $\begin{array}{l}\text { A progressão na linguagem processa-se na se- } \\
\text { qüência correta, mas em ritmo mais lento, sendo } \\
\text { o desempenho semelhante ao de uma criança de } \\
\text { idade inferior. }\end{array}$ \\
Dissociação & $\begin{array}{l}\text { Existe uma diferença significativa entre a evolução } \\
\text { da linguagem e das outras áreas do desenvolvi- } \\
\text { mento. }\end{array}$ \\
Desvio & $\begin{array}{l}\text { O padrão de desenvolvimento é mais alterado: } \\
\text { verifica-se uma aquisição qualitativamente anô- } \\
\text { mala da linguagem. É um achado comum nas } \\
\text { perturbações da comunicação do espectro do au- } \\
\text { tismo. }\end{array}$ \\
\hline
\end{tabular}

A etiologia das dificuldades de linguagem e aprendizagem é diversa e pode envolver fatores orgânicos, intelectuais/cognitivos e emocionais (estrutura familiar relacional), ocorrendo, na maioria das vezes, uma inter-relação entre todos esses fatores. Sabe-se que as dificuldades de aprendizagem também podem ocorrer em concomitância com outras condições desfavoráveis (retardo mental, distúrbio emocional, problemas sensório-motores) ou, ainda, ser acentuadas por influências externas, como, por exemplo, diferenças culturais, instrução insuficiente ou inapropriada12,13 (Tabela 3).

\section{Linguagem e epilepsia}

Os efeitos da epilepsia, das crises convulsivas e das descargas eletroencefalográficas sobre a linguagem têm sido discutidos em diversos estudos. Pode-se dizer que três são os distúrbios mais relatados em pacientes epilépticos: as disfasias do desenvolvimento associadas a epilepsia; as afasias críticas (agudas), onde ocorre uma alteração transitória da função cognitiva; e a afasia epiléptica adquirida (síndrome de Landau-Kleffner) ${ }^{14,15}$. A afasia epiléptica adquirida é caracterizada pela deteriorização da linguagem na infância associada a crises ou atividade eletroencefalográfica epileptiforme anormal. Esse tipo de afasia muitas vezes é confundido com síndrome autística ou deficiência auditiva. Além da deteriorização da linguagem e da agnosia auditiva, observam-se alterações de comportamento, incluindo traços autistas. Por isso, devemos estar atentos a qualquer criança que apresente regressão de linguagem, devendo esta ser avaliada cuidadosamente (para que seja feito um diagnóstico diferencial) e encaminhada para o tratamento adequado ${ }^{16-18}$.

\section{Linguagem e autismo}

A regressão da linguagem é observada na síndrome de Landau-Kleffner e na regressão autística $14,19,20$. Recentes estudos focados na linguagem verbal de crianças com 
Tabela 3 - Etiologia dos distúrbios da linguagem oral e escrita

\begin{tabular}{|c|c|}
\hline Distúrbios & Descrição \\
\hline Causa ambiental & Fatores de risco sociais e emocionais. \\
\hline $\begin{array}{l}\text { Atraso isolado da linguagem } \\
\text { expressiva ("constitucional") }\end{array}$ & $\begin{array}{l}\text { Atraso de causa não-demonstrável associado a compreensão, pragmática } \\
\text { e desenvolvimento não-verbal normais. }\end{array}$ \\
\hline Déficit cognitivo & $\begin{array}{l}\text { Nos primeiros anos, a evolução da linguagem na criança com atraso de desenvolvi- } \\
\text { mento é semelhante à da criança normal, mas num ritmo inferior. }\end{array}$ \\
\hline Déficit auditivo & $\begin{array}{l}\text { Influencia a aquisição da linguagem após } 6-9 \text { meses, quando observam-se alterações } \\
\text { da vocalização (perda da qualidade vocal, consoantes que desaparecem ou não } \\
\text { chegam a surgir, modificação da sonoridade das vogais) até que apenas sons } \\
\text { primitivos e guturais acabam por persistir. }\end{array}$ \\
\hline Autismo & $\begin{array}{l}\text { Pode ocorrer ecolalia imediata ou tardia, perseveração (persistência inapropriada no } \\
\text { mesmo tema) em associação a alterações da comunicação não-verbal, comportamen- } \\
\text { tos estereotipados e perseverantes, interesses restritos e/ou não-usuais e compro- } \\
\text { metimento da capacidade social. }\end{array}$ \\
\hline $\begin{array}{l}\text { Alterações específicas } \\
\text { da linguagem }\end{array}$ & $\begin{array}{l}\text { Caracterizam-se por limitações significativas da função lingüística que não podem ser } \\
\text { atribuídas a perda auditiva, déficit cognitivo ou alterações da estrutura e função } \\
\text { fonadora. É um diagnóstico de exclusão. }\end{array}$ \\
\hline
\end{tabular}

espectro autista enfatizam traços anômalos da fala, como a escolha de palavras pouco usuais, inversão pronominal, ecolalia, discurso incoerente, crianças não-responsivas a questionamentos, prosódia aberrante e falta de comunicação 21,22 . Muitos estudos atribuem a ausência de fala em alguns indivíduos ao grau de severidade do autismo, à tendência a retardo mental ou a uma inabilidade de decodificação auditiva da linguagem ${ }^{21}$. No autismo, a compreensão e a pragmática estão invariavelmente afetadas, e os achados incluem prosódia aberrante, ecolalia imediata e/ou tardia e perseveração (persistência inapropriada no mesmo tema). Outros sintomas estão também presentes, distinguindo essas crianças daquelas com apenas atraso de linguagem; esses sintomas incluem, particularmente, perturbações da comunicação não-verbal, comportamentos estereotipados e perseverantes, interesses restritos e/ou inusuais e alteração das capacidades sociais ${ }^{23}$. Concluímos, com isso, que a regressão de linguagem na infância se caracteriza por um distúrbio grave, com morbidades significativas a longo prazo 24 .

\section{Intervenção na criança com distúrbio da linguagem}

A produção da fala e linguagem pode ser considerada adequada ou não de acordo com a idade cronológica. Para avaliá-la, é necessário levar em conta os aspectos cognitivos e emocionais do desenvolvimento, que poderão indicar ou não a severidade do caso, bem como a necessidade de orientação especializada à família e/ou terapia fonaudiológica ${ }^{24}$. Sabe-se que a estimulação precoce da linguagem pode prevenir distúrbios de aprendizagem, dislexia e problemas de desenvolvimento. Pesquisas vêm demonstrando a importância dos 3 primeiros anos de vida no desenvolvimento do cérebro humano 25,26 .

São princípios básicos da intervenção na criança a avaliação do desenvolvimento da linguagem em todos os seus níveis, a orientação à família e escola e a terapia propriamente dita 1,24 . Esta pode ser dividida em terapia da fala (onde serão abordados objetivos como desvios fonéticos e fonológicos), terapia de voz (disfonias), terapia de motricidade oral (distúrbios de alimentação, respiração e mobilidade de órgãos fonoarticulatórios), terapia de linguagem oral (onde o enfoque pode estar centrado na expressão e/ou recepção de linguagem) e terapia de linguagem escrita (dislexias, disortografias e disgrafias).

Todas as atividades de estimulação dentro da terapia fonoaudiológica infantil devem ser realizadas de forma lúdica, através de jogos e brincadeiras, para que a criança sinta prazer nas técnicas propostas. Também é recomendável envolver a família e, quando necessário, a escola ${ }^{1}$.

A estimulação através de canto, conversa, brincadeiras e leitura propicia a aquisição de habilidades que favorecem o desenvolvimento. Para que comece a ocorrer um processo de comunicação, a criança deverá se sentir motivada. Deverá existir o que se chama de intenção comunicativa (através da fala serão conseguidos objetos de interesse da criança). Este aspecto surge através do contato diário com as pessoas e da estimulação que essa interação propicia. Também devemos considerar a importância da amamenta- 
ção materna, alimentação com textura e consistência adequadas nas diferentes fases e a não-existência de hábito de sucção de dedo ou chupeta além dos 2 anos. Todos esses fatores contribuem para uma musculatura orofacial adequada à produção da fala. A família tem papel fundamental na estimulação da linguagem, e cabe ao médico e/ou terapeuta envolvê-la ou permitir envolver-se pela família26.

\section{Aprendizagem}

Do ponto de vista do construtivismo, aprendizagem é construção, ação e tomada de consciência da coordenação das ações. O aluno irá construir seu conhecimento através de uma história individual já percorrida, tendo uma estrutura, ou com base em condições prévias de todo o aprender, além de ser exposto ao conteúdo necessário para seu aprendizado $^{27}$.

Em relação ao aprendizado específico da leitura e da escrita, este está vinculado a um conjunto de fatores que adota como princípios o domínio da linguagem e a capacidade de simbolização, devendo haver condições internas e externas necessárias ao seu desenvolvimento ${ }^{28}$.

\section{Desenvolvimento normal}

A habilidade de leitura é verificada através da capacidade de decodificação, fluência e compreensão da escrita 29 . 0 processo normal de leitura ocorre em duas etapas. Inicialmente, é realizada a análise visual, através do processamento vísuo-perceptivo do estímulo gráfico. Em seguida, ocorre o processamento lingüístico da leitura, onde, através da via não-lexical, é feita a conversão grafema-fonema e, pela via lexical, é feita a leitura global da palavra com acesso ao significado 30,31 . A criança tem que descobrir que há letras que não representam o som da fala, visto que "a leitura alfabética associa um componente auditivo fonêmico a um componente visual gráfico, o que é denominado de correspondência grafofonêmica"32. É necessária a conscientização da estrutura fonêmica da linguagem (decomposição das palavras) e das unidades auditivas que são representadas por diferentes grafemas ${ }^{33}$.

\section{Bases neurobiológicas}

O processo de aquisição da linguagem escrita, assim como o da linguagem oral, envolve diversas regiões cerebrais, entre elas a área parieto-occipital. Na região occipital, o córtex visual primário é o responsável pelo processamento dos símbolos gráficos, e as áreas do lobo parietal são responsáveis pelas questões vísuo-espaciais da grafia. Essas informações processadas são reconhecidas e decodificadas na área de Wernicke, responsável pela compreensão da linguagem, e a expressão da linguagem escrita necessita da ativação do córtex motor primário e da área de Broca. Para todo este processo ocorrer, é importante que as fibras de associação intra-hemisféricas estejam intactas ${ }^{7}$.

Em uma pesquisa, observou-se ativação cerebral de pessoas normais durante a leitura de pseudopalavras nas seguintes regiões: região frontal inferior esquerda; região parietotemporal, envolvendo os giros angular, supramarginal e a porção posterior de giro temporal superior; e regiões occipitotemporais, envolvendo porções mesiais e inferiores do giro temporal e giro occipital ${ }^{27}$. O mesmo estudo foi realizado em disléxicos, sendo constatado um aumento de ativação no giro frontal inferior e pouca ativação em regiões posteriores.

Pesquisadores relatam que, em relação aos mecanismos neurológicos das dificuldades de leitura, alterações referentes à assimetria hemisférica geram uma organização atípica do hemisfério direito em crianças e adolescentes com dislexia ${ }^{34}$.

Disléxicos apresentam uma desconexão temporo-parieto-occipital e uma desconexão com o córtex frontal esquerdo, assim como anormalidades do córtex têmporo-parietal e do cerebelo em relação a outras regiões do cérebro ${ }^{33}$.

\section{Dificuldades de aprendizagem da linguagem escrita na infância}

Dificuldades de aprendizagem referem-se a alterações no processo de desenvolvimento do aprendizado da leitura, escrita e raciocínio lógico-matemático, podendo estar associadas a comprometimento da linguagem oral ${ }^{34-36}$.

Ao se estudar alterações no processo de aprendizagem da linguagem oral, freqüentemente verifica-se a ocorrência de posteriores dificuldades de aprendizagem da leitura e escrita. Da mesma forma, ao se investigar os fatores que antecedem as dificuldades de leitura e escrita, surgem questionamentos a respeito das dificuldades de aprendizado da linguagem. Ressalta-se que, entre as alterações de linguagem oral existentes na infância, são as dificuldades fonológicas, e não as articulatórias, que podem ocasionar prejuízos no aprendizado posterior da leitura e da escrita ${ }^{37}$.

\section{Dislexia}

A leitura e a escrita envolvem habilidades cognitivas complexas, além de capacidade de reflexão sobre a linguagem no que se refere aos aspectos fonológicos, sintáticos, semânticos e pragmáticos.

As crianças, ao iniciar a alfabetização, já dominam a linguagem oral, sendo capazes de iniciar o aprendizado da escrita. Porém, sabe-se que existem regras mais específicas e próprias da escrita, havendo, então, maiores dificuldades no seu aprendizado 38 .

No Brasil, cerca de $40 \%$ das crianças em séries iniciais de alfabetização apresentam dificuldades escolares, e, em países mais desenvolvidos, a porcentagem diminui $20 \%$ em relação ao número total de crianças também em séries iniciais 38,39 . Sabe-se que se um aluno com dificuldades de aprendizagem for bem conduzido pelos profissionais de saúde e educação, em conjunto com a família, poderá obter êxito nos resultados escolares ${ }^{13}$.

É importante ressaltar que existe uma combinação dos fenômenos biológicos e ambientais no aprendizado da linguagem escrita, envolvendo a integridade motora, a integridade sensório-perceptual e a integridade socioemocional (possibilidades reais que o meio oferece em termos 
de quantidade, qualidade e freqüência de estímulos). Além disso, o domínio da linguagem e a capacidade de simbolização também são princípios importantes no desenvolvimento do aprendizado da leitura e da escrita 40,41 .

Sendo considerada uma alteração de aprendizagem, a dislexia caracteriza-se por dificuldades específicas na realização da leitura e da escrita, havendo, de maneira geral, dois tipos de dislexia: a dislexia de desenvolvimento e a dislexia adquirida 38,42 . A primeira refere-se a alterações no aprendizado da leitura e escrita com origem institucional, ou seja, ambiental, referente à forma de aprendizado escolar. Nesses casos, ocorre diminuição da capacidade de leitura associada a disfunção cerebral, havendo uma alteração específica na aquisição das habilidades de leitura e conseqüente dificuldade no aprendizado da leitura ${ }^{33}$. Existem autores que consideram fatores genéticos como uma das causas de dislexia de desenvolvimento. Já na dislexia adquirida, o aprendizado da leitura e da escrita, que foi adquirido normalmente, é perdido como resultado de uma lesão cerebral.

Vários são os fatores ainda em estudo que descrevem as causas da dislexia de desenvolvimento - entre eles, déficits cognitivos, fatores neurológicos (neuroanatômicos e neurofisiológicos), prematuridade e baixo peso ao nascimento, influências genéticas e ambientais. Sabe-se, porém, que fatores externos (ambientais) não podem ser separados de problemas neurológicos, visto que aspectos tais como instrução inadequada, distúrbios emocionais e pobreza de estímulos na infância podem causar diferenças no desenvolvimento neurológico e cognitivo que precedem dificuldades severas de leitura $41,43,44$.

As dislexias podem ser divididas em dois tipos: central e periférica (Tabela 4). Na primeira, ocorre o comprometimento do processamento lingüístico dos estímulos, ou seja, alterações no processo de conversão da ortografia para fonologia. Na segunda, ocorre o comprometimento do sistema de análise vísuo-perceptiva para leitura, havendo prejuízos na compreensão do material lido.

Entre as dislexias centrais, ressaltam-se a fonológica, a de superfície e a profunda; já as dislexias periféricas incluem a dislexia atencional, a por negligência e a literal (pura) 29 .

Em relação às dislexias de desenvolvimento, as mais comuns são a dislexia fonológica e a de superfície, já mencionadas anteriormente, e a dislexia semântica. Esta se caracteriza pela preservação da leitura em voz alta, sem erros de decodificação (fonema-grafema), porém com pobreza na compreensão da escrita 45 .

Tabela 4 - Classificação das dislexias centrais e periféricas

\begin{tabular}{|c|c|c|}
\hline Dislexias & Características clínicas & Características neuroanatômicas \\
\hline Dislexia fonológica & $\begin{array}{l}\text { Incapacidade de decodificação fonológica. } \\
\text { Danos na via de conversão grafema-fonema. } \\
\text { Dificuldades em tarefas de memória fonológica. } \\
\text { Desempenho muito ruim na leitura de estímulos } \\
\text { não-familiares e pseudopalavras } \\
\text { (palavras não-reais). }\end{array}$ & $\begin{array}{l}\text { Sabe-se muito pouco sobre as áreas } \\
\text { neuroanatômicas essenciais para } \\
\text { o funcionamento adequado do } \\
\text { processamento perilexical, não } \\
\text { havendo evidências de disfunções } \\
\text { neuroanatômicas específicas. }\end{array}$ \\
\hline Dislexia de superfície & $\begin{array}{l}\text { Comprometimento da via lexical. } \\
\text { Os estímulos são lidos através do processo } \\
\text { fonológico (ex.: "tóxico" é lido "tóchico"), } \\
\text { havendo uma incapacidade no tratamento } \\
\text { ortográfico da informação. }\end{array}$ & $\begin{array}{l}\text { Evidências de disfunção na região } \\
\text { temporal média e póstero-superior } \\
\text { do hemisfério esquerdo. }\end{array}$ \\
\hline Dislexia profunda & $\begin{array}{l}\text { Bloqueio na via não-lexical. } \\
\text { Ausência de leitura de não-palavras. } \\
\text { Maior facilidade para leitura de } \\
\text { palavras concretas e freqüentes. }\end{array}$ & $\begin{array}{l}\text { Alguns autores relatam a ocorrência } \\
\text { de lesões múltiplas no hemisfério } \\
\text { esquerdo, e outros sugerem que existem } \\
\text { habilidades de leitura residuais no } \\
\text { hemisfério direito devido à extensa lesão } \\
\text { em hemisfério dominante. }\end{array}$ \\
\hline Dislexia atencional & $\begin{array}{l}\text { Preservação da leitura de palavras isoladas. } \\
\text { Dificuldades na leitura de vários itens quando } \\
\text { apresentados simultaneamente. }\end{array}$ & Lesões no lobo parietal esquerdo. \\
\hline Dislexia por negligência & $\begin{array}{l}\text { Dificuldades na leitura no campo visual do lado } \\
\text { contralateral ao da lesão cerebral. }\end{array}$ & $\begin{array}{l}\text { Lesão na região da artéria cerebral } \\
\text { média do hemisfério direito envolvendo } \\
\text { lobos frontal, temporal e parietal. }\end{array}$ \\
\hline Dislexia literal (pura) & Leitura letra por letra preservada. & $\begin{array}{l}\text { Lesões occipitais inferiores extensas } \\
\text { à esquerda. }\end{array}$ \\
\hline
\end{tabular}


Várias pesquisas vêm fornecendo evidências de déficits fonológicos em dislexias de desenvolvimento. No entanto, recentes estudos demonstraram a existência de múltiplos déficits de processamento temporal nas dislexias. De fato, disléxicos mostram anormalidades visuais e auditivas que podem resultar de problemas generalizados na percepção e na seleção de estímulos.

Crianças com dislexia apresentam alterações auditivas e visuais referentes à orientação espacial. Esses achados sugerem que déficits na atenção da seleção espacial podem desorganizar o desenvolvimento de representações fonológicas e ortográficas que são essenciais para o aprendizado da leitura ${ }^{46}$.

Em uma pesquisa realizada pelo Institute of Cognitive Neuroscience (Londres), foram investigados 16 disléxicos adultos e 16 controles através de uma bateria de testes psicométricos, fonológicos, auditivos, visuais e cerebelares. Dados individuais revelaram que todos os disléxicos apresentaram déficits fonológicos, 10 mostraram déficits auditivos, quatro tinham déficits motores, e dois tinham déficits visuais. Esses achados sugerem que déficits fonológicos podem aparecer na ausência de qualquer outra alteração motora ou sensorial e são suficientes para causar um prejuízo significativo, como foi demonstrado em cinco dos 16 disléxicos 47 .

\section{Dislexia e distúrbio da atenção/hiperatividade}

A grande maioria das crianças com déficit de atenção/ hiperatividade apresenta dificuldades escolares, podendo haver a concomitância dessas alterações com dislexia do desenvolvimento.

Realizou-se um estudo comparando grupos de crianças com dificuldades de leitura sem déficit de atenção/hiperatividade, crianças somente com déficit de atenção e hiperatividade, crianças com dificuldade de leitura e déficit de atenção e hiperatividade, e crianças sem nenhum prejuízo. Foram investigados aspectos referentes ao processamento auditivo do lobo temporal dessas crianças. Os resultados da pesquisa não indicaram um déficit nas funções temporais auditivas em crianças com dificuldades de leitura, mas sugeriram que a presença de déficit de atenção e hiperatividade é um fator significante na performance de crianças com dificuldades de leitura ${ }^{48}$. Outra pesquisa realizada na Holanda (Department of Special Education, Vrije Universiteit, Amsterdã) mostrou que os déficit inibitórios em disléxicos lexicais podem ser atribuídos a disfunções em estruturas cerebrais fronto-centrais envolvidas em inibições motoras, sugerindo que possa haver uma associação entre dislexia lexical e déficit de atenção/hiperatividade, já que os dois grupos apresentam disfunção executiva 45 .

\section{Dislexia e baixo peso ao nascimento}

Em relação às crianças que nascem com baixo peso, existe uma associação entre a presença de doença cerebral periventricular e baixa performance em testagens de leitura e habilidades de soletração ${ }^{49}$. Em um estudo realizado nos Estados Unidos, pesquisadores buscaram encontrar associações entre dificuldades de leitura e seus potenciais fatores de risco em meninos e meninas. Os resultados indicaram que meninas com baixo peso ao nascimento apresentam duas vezes mais probabilidade de desenvolver alterações de leitura ${ }^{50}$. Salienta-se que existem diferenças na utilização cortical durante a leitura em crianças com baixo peso ao nascimento ${ }^{51}$.

\section{Influências genéticas na dislexia}

Sabendo-se que existem alguns indivíduos que têm predisposição genética para dificuldades de leitura, as dislexias vêm sendo estudadas em função de seus aspectos genéticos. A leitura está sendo relacionada a cromossomos específicos $(6,1,2$ e 15), apesar de, até recentemente, não haver evidências de genes específicos responsáveis pela capacidade ou incapacidade de leitura ${ }^{39}$.

Achados mais recentes, pesquisados através do Projeto Genoma Humano, evidenciaram quatro genes de suscetibilidade à dislexia: DYX1, DYX2, DYX3 e DYX4. São genes em diferentes posições, suspeitando-se do caráter heterogêneo dos transtornos de leitura 52 .

Uma outra pesquisa, que está sendo realizada pelo neuropsicólogo Frank Wood, da Universidade de Forest Wake, revela que outros cromossomos (6, 1, 2 e 15) têm relações com a incapacidade de algumas crianças no processamento do texto ${ }^{52}$. Mais especificamente, sabe-se que existe um lócus nos cromossomos 6 e 18 que tem mostrado fortes e replicáveis efeitos nas habilidades de leitura ${ }^{53}$.

É importante ressaltar que o progresso no entendimento do papel da genética na dislexia pode ajudar a diagnosticar e tratar crianças suscetíveis a tais dificuldades com maior efetividade e rapidez.

\section{Outras alterações da linguagem escrita - disgrafia e disortografia}

Devendo ser analisada através de diferentes tarefas (cópia, ditado e escrita espontânea), a expressão da escrita também pode evidenciar alterações como a disgrafia, ou seja, alterações no traçado das letras, e a disortografia, que se refere a alterações ortográficas na escrita das palavras não esperadas para determinada faixa etária e escolaridade. A disgrafia e a disortografia podem estar associadas ou não às dislexias.

\section{Intervenções}

São princípios básicos do trabalho em linguagem escrita com a criança: estimular a descoberta e utilização da "lógica" de seu pensamento na construção de palavras e textos e na representação de fonemas; oferecer oportunidades para a escrita e leitura espontâneas; explorar constantemente as diversas funções da escrita (não apenas produção textual mas também cartas e bilhetes); e explicitar as diferenças entre língua falada e língua escrita. É importante que a criança tenha adequada consciência de que a fala e a escrita são formas diferentes de expressão da linguagem. 
Conforme visto anteriormente, alterações nos processos perceptivos da leitura ou nos processos psicolingüísticos (lexicais, visuais, fonológicos, sintáticos ou semânticos) podem acarretar dificuldades de leitura, estando a elaboração do programa de reabilitação diretamente relacionada com a avaliação dos processos deficitários na criança ${ }^{35}$. Em pacientes com dislexia de superfície, geralmente se utiliza uma estratégia lexical, e em disléxicos fonológicos, a intervenção mais apropriada é a estimulação da conversão grafema-fonema (não-lexical) ${ }^{54}$. Salienta-se a importância da estimulação da consciência fonológica em pré-leitores, visto que muitos estudos demonstram sua eficiência no aprendizado da leitura 55 .

A principal indicação atual para o tratamento de crianças com dificuldades de linguagem escrita é a intervenção direta nas habilidades de leitura, associada a atividades relacionadas ao processamento fonológico da linguagem. Práticas anteriores buscavam estimular habilidades consideradas pré-requisitos para o aprendizado da leitura, como percepção vísuo-espacial, habilidades psicomotoras, etc. ${ }^{56}$.

Todas as atividades de estimulação da linguagem escrita devem ser realizadas de forma lúdica, através de jogos e brincadeiras, para que a criança sinta prazer em ler e escrever. Em casa, o estímulo deve ser iniciado com a leitura de histórias infantis pelos pais para os filhos, a estimulação de jogos de rimas, que ajudam na consciência fonológica, jogos com letras e desenhos, para a criança já ir se familiarizando com a escrita, leitura de rótulos e propagandas - enfim, nunca se deve obrigar uma criança a ler um livro, e sim fazê-la ter vontade de ler e conhecer a sua história29.

\section{Conclusão}

Sabe-se que as causas de alterações de linguagem e de dificuldades de aprendizagem podem ser variadas, apesar de existirem muitos estudos indicando fatores neurológicos para tais problemas. Avanços na compreensão da neurobiologia dos processos de desenvolvimento da linguagem e aprendizagem certamente irão contribuir para uma melhoria na abordagem terapêutica desses pacientes. A sistemática da investigação em busca do diagnóstico preciso pode direcionar o profissional de saúde na escolha do melhor tratamento indicado para cada caso.

\section{Referências}

1. Landry SH, Smith KE, Swank PR. Environmental effects on language development in normal and high-risk child population. Semin Pediatr Neurol. 2002;9(3):192-200.

2. Castaño J. Bases neurobiológicas del lenguaje y sus alteraciones. Rev Neurol. 2003;36(8):781-5.

3. Nogueira $S$, Fernández B, Porfírio $H$, Borges L. A criança com atraso na linguagem. Saúde Infantil. 2000;22(1):5-16.

4. Rescorla L, Mirak J. Normal language acquisition. In: Bodensteiner JB, editor. Seminars in Pediatric Neurology. Philadelphia: W. B. Saunders Co.; 1997. p. 275-92.

5. Cervera-Mérida JF, Ygual-Fernández A. Intervención logopédica em los transtornos fonológicos desde el paradigma psicolingüístico del procesamiento del habla. Rev Neurol. 2003;36 Supl 1:39-53.
6. Costa DI, Azambuja LA, Nunes ML. Avaliação do Desenvolvimento Neuropsicomotor. In: Nunes ML, Marrone ACH. Semiologia Neurológica. Porto Alegre: EDIPUCRS; 2002. p. 351-360.

7. Kandel DB, Johnson JG, Bird HR, Canino G, Goodman SH, Lahey $\mathrm{BB}$, et al. Psychiatric disorders associated with substance use among children and adolescents: findings from the Methods for the Epidemiology of Child and Adolescent Mental Disorders (MECA) Study. J Abnorm Child Psychol. 1997;25(2):121-32.

8. Casas-Fernández C. Lenguaje y epilepsia. Rev Neurol Clin. 2000;1:103-114.

9. Geschwind N, Galaburda AM. Cerebral Lateralization. Biological Mechanisms, Associations and Pathology. Arch Neurol. 1995:42:428-59.

10. Westerveld M, Sass KJ, Chelune GJ, Hermann BP, Barr WB, Loring DW, et al. Temporal lobectomy in children: cognitive outcome. Neurosurgery. 2000;92:24-30.

11. Caputte AJ, Accardo PJ. Language Assessment. In: Caputte AJ, Accardo PJ, editors. Developmental and Disabilities in Infancy and Childhood. Baltimore: Paul H Brookes Publishing Co.; 1991. p. 165-79.

12. Undheim AM. Dyslexia and psychosocial factors. a follow-up study of young Norwegian adults with a history of dyslexia in childhood. Nord J Psychiatry. 2003;57(3):221-6.

13. Polity E. Dificuldade de Ensinagem: Que História é Essa? Fonoaudiologia Atual. 2003;(23):60-8.

14. Shinnar S, Rapin I, Arnold S, Tuchman R, Shulman L, BallananGill, et al. Language regression in childhood. Pediatr Neurol. 2000;24(3):185-91.

15. Campos-Castelló J. Epilepsia y transtornos del lenguaje. Rev Neurol. 2000;30 Supl 1:89-94.

16. Stefanatos GA, Kinsbourne M, Wasserstein J. Acquired epileptiform aphasia: a dimensional view of Landau-Kleffner syndrome and the relation to regressive autistic spectrum disorders. Neuropsychol Dev Cogn Sect C Child Neuropsychol. $2002 ; 8(3): 195-228$.

17. Wheless JW, Simos PG, Butler IJ. Language dysfunction in epileptic conditions. Semin Pediatr Neurol. 2002;9(3):218-28.

18. Ribeiro KMN, Assumpção FB, Valente KDR. Síndrome de LandauKleffner e regressão autística. Arq Neuro-Psiquiatr. 2002;60(3B): 835-9.

19. Tuchman R, Rapin I. Epilepsy in autism. Lancet Neurol. 2002; $1(6): 352-8$

20. Palmini A, Da Costa JC, Paglioli-Neto E, Portuguez M, Martinez $\mathrm{JV}$, Paglioli E, et al. Reversible and irreversible autistic regression related to epilepsy and epileptiform EEG discharges: physiopatogenic considerations and preliminary report of 5 cases. J Epilepsy Clin Neurophysiol. 2002;8(4):221-8.

21. Rapin I, Dunn M. Update on language disorders of individuals on the autistic spectrum. Brain Dev. 2003;25(3):166-72.

22. Botting N, Conti-Ramsden G. Autism, primary pragmatic difficulties, and specific language impairment: can we distinguish them using psycholinguistic markers? Dev Med Child Neurol. 2003; 45(8):515-24

23. Wilson S, Djukic A, Shinnar S, Dharmani C, Rapin I. Clinical characteristics of language regression in children. Dev Med Child Neurol. 2003;45(8):508-14.

24. Becker F. Modelos Pedagógicos e Modelos Epistemológicos. In: Silva LH, Azevedo CJ. Paixão de aprender II. Petrópolis, RJ: Vozes; 1995.

25. Tedesco MRM. Diagnóstico e terapia dos distúrbios do aprendizado da leitura e escrita. In: Otalilio LP. Tratado de Fonoaudiologia. São Paulo: Roca; 1997.

26. Shaywitz SE, Shaywitz BA. Dyslexia (specific reading disability). Pediatr Rev. 2003;24(5):147-53.

27. Shaywitz SE. Dyslexia. New Engl J Med. 1998;338(5):307-12.

28. Mansur LL, Senaha MLH. Distúrbios de linguagem oral e escrita e hemisfério esquerdo. In: Nitrini R, Caramelli P, Mansur LL. Neuropsicologia: das bases anatômicas à reabilitação. São Paulo: Clínica Neurológica do Hospital das Clínicas da Faculdade de Medicina da Universidade de São Paulo; 1996.

29. Capellini AS, Poleti FS, Renzo, Arruda PD, Pieroni R, Miurd RY, et al. Formação de interlocutores para a construção da linguagem escrita: manual de orientação a pais e professores de crianças com dificuldades escolares. Temas sobre Desenvolvimento 2000;9(50):33-9.

30. Démont $\mathrm{E}$. Consciência fonológica, consciência sintática: que papel (ou papéis) desempenha na linguagem eficaz da leitura. In: Gregóire J, Piérart B. Avaliação dos problemas de leitura: os novos modelos teóricos e suas implicações diagnósticas. Porto Alegre: Artes Médicas; 1997. 
31. Heim S, Eulitz C, Elbert T. Altered hemispheric asymmetry of auditory P100m in dyslexia. Eur J Neurosci. 2003;17(8): 1715-22.

32. Lozano A, Ramirez M, Ostrosky-Solis F. The neurobiology of developmental dyslexia: a survey. Rev Neurol. 2003;36(11): 1077-82.

33. Medow N, Olitsky SE, De Respinis P. Learning disorders. J Pediatr Ophthalmol Strabismus. 2003;40(2):92-4.

34. Hayes EA, Warrier CM, Nicol TG, Zecker SG, Kraus N. Neural plasticity following auditory training in children with learning problems. Clin Neurophysiol. 2003;114(4):673-84.

35. Garcia JN. Manual de Dificuldades de Aprendizagem. Porto Alegre: Artes Médicas, 1998.

36. Nunes $T$, Buarque $L$, Bryant P. Dificuldade na aprendizagem da leitura: teoria e prática. São Paulo: Cortez; 1997.

37. Spreen O, Risser AH, Edgel D. Developmental Neuropsychology. New York: Oxford University. Press; 1995.

38. Ciasca AS. Distúrbios e dificuldades de aprendizagem: diagnóstico através de bateria lúria nebraska para crianças BLN-C. In: Damasceno BP, Coutry MI. Temas em Neuropsicologia e Neurolingüística. São Paulo: Tec Art; 1995.

39. Rutkowski JS, Grewther DP, Grewther SG. Change detection is impaired in children with dyslexia. J Vis. 2003;3(1):95-105.

40. Mathes PG, Denton CA. The prevention and identification of reading disability. Semin Pediatr Neurol. 2002;9(3):185-91.

41. Pinheiro AMV. Dificuldades específicas de leitura: a identificação de déficits cognitivos e a abordagem do processamento de informação. Psicologia: Teoria e Pesquisa. 1995;11(2):107-15.

42. McCandliss BD, Noble KG. The development of reading impairment: a cognitive neuroscience model. Ment Retard Dev Disabil Res Rev. 2003;9(3):196-204.

43. Landry SH, Smith KE, Swank PR. Environmental effects on language development in normal and high-risk child population. Semin Pediatr Neurol. 2002;9(3):192-200.

44. van der Schoot M, Licht R, Horsley TM, Sergeant JA. Frontocentral dysfunction in reading disability depend on subtype: guessers but not spellers. Dev Neuropsychol. 2002;22(3): 533-64.

45. Facoetti A, Lorusso ML, Paganoni P, Cattaneo C, Galli R, Umilta $C$, et al. Auditory and visual automatic attention deficits in developmental dyslexia. Brain Res Cogn Brain Res. 2003; 16(2):185-91.

46. Ramus F, Rosen S, Dakin SC, Day BL, Castellote JM, White S, et al. Theories of developmental dyslexia: insights from a multiple case study of dyslexic adults. Brain. 2003;126(Pt 4): 841-65.
47. Breier JI, Fletcher JM, Foorman BR, Klaas P, Gray LC. Auditory temporal processing in children with specific reading disability with and without attention deficit/hiperactivity disorder. J Speech Lang Hear Res. 2003;46(1):31-42.

48. Downie AL, Jakobson LS, Frisk V, Ushycky I. Periventricular brain injury, visual motion processing, and reading and spelling abilities in children who were extremely low birthweight. J Int Neuropsychol Soc. 2003;9(3):440-9.

49. St Sauver JL, Katusic SK, Barbaresi WJ, Colligan RC, Jacobsen $\mathrm{S}$. Boy/girl differences in risk for reading disability: potential clues? Am J Epidemiology. 2001;154(9):787-94.

50. Khan SC, Frisk V, Taylor MJ. Neurophysiological measures of reading difficulty in very-low-birthweight children. Psychophysiology. 1999;36(1):76-85.

51. van Hout A. Orientações neurológicas e neuropsicológicas: reeducação dos erros e dos distúrbios cognitivos. In: van Hout A, Estienne F. Dislexias: Descrição, Avaliação, Explicação e Tratamento. Porto Alegre: Artes Médicas; 2001.

52. Pedagogia em Foco [site na Internet]. Fortaleza: Pedagogia em Foco; c1998-2004 [atualizado em 06/01/2003; citado em 05/ 12/2003] Martins V. Dislexia e o projeto genoma humano; [aproximadamente 3 telas]. Disponível em: http:// www.pedagogiaemfoco.pro.br/spdlx05.htm.

53. Francks $C$, MacPhie IL, Monaco AP. The genetic basis of dyslexia. Lancet Neurol. 2002;1(8):483-90.

54. Byrne B, Fielding-Barnsley R. Phonetic awareness and letter knowledge in the child's acquisition of the alphabetic principle. J Educ Psychol. 1989;81:313-21.

55. Capovilla AGS, Capovilla FC. Efeitos do treino de consciência fonológica em crianças de baixo nível sócio-econômico. Psicologia: Reflexão e Crítica. 2000;13(1):7-24

56. Salles JF, Parente MA, Machado SS. As dislexias de desenvolvimento: aspectos neuropsicológicos e cognitivos. Revista Interações - Universidade de São Marcos, São Paulo/ SP. No Prelo 2003.

Correspondência:

Magda Lahorgue Nunes

Serviço de Neurologia do HSL-PUCRS

Av. Ipiranga, 6690/220

CEP 90610-000 - Porto Alegre, RS

Fone/Fax: (51) 3339.4936

E-mail: nunes@pucrs.br 